\title{
A Homothetic Scaling Criteria for Synchronous Reluctance Machines Design
}

\author{
Mukhammed Murataliyev, Student Member, IEEE, Michele Degano, Senior Member, IEEE, \\ Mauro Di Nardo, Member, IEEE, Dmytro Prystupa, Member, IEEE, Wang Shuo, Member, \\ IEEE, Giampaolo Buticchi, Senior Member, IEEE, He Zhang, Senior Member, IEEE, Chris \\ Gerada, Senior Member, IEEE, Michael Galea, Senior Member, IEEE
}

\begin{abstract}
${ }^{1}$ Abstract-This paper proposes a concept for homothetic scaling of Synchronous Reluctance (SynRel) machines with the aim to generate a design for a wide range of power ratings. A generalized modeling approach, based on the saliency ratio, is presented in detail to analytically evaluate the magnetic behavior of the scaled SynRel machines. The analytical model has been applied to a wide range of machines and validated through finite element analysis. General scaling functions are derived to size and evaluate the performance of the scaled machines using the data resulting from the analytical model. The accuracy of the proposed functions is validated, for a range of operating conditions, comparing the results with the experimental measurement carried out on two 4-poles SynRel prototypes. These have been designed using the homothetic method proposed, which has been proven to be a quick and accurate preliminary sizing tool for SynRel motors.

Index Terms - Synchronous Reluctance Machines, Analytical modelling, Saliency ratio, Sizing Methods, Homothetic scaling.
\end{abstract}

\section{INTRODUCTION}

$\mathrm{I}^{\mathrm{n}}$ $\mathrm{n}$ recent years, there is a growing interest for a high efficiency electric motors without, or with reduce content of, permanent magnets (PMs) for the industrial applications. The Synchronous Reluctance (SynRel) machine is one of the most promising candidates that can meet the requirements of efficient and low cost drive [1]. The key benefits of this technology are a rotor structure made of flux barriers and iron parts, without excitation coils or PMs, like induction motors and PM machines, respectively [2]. This leads to a cost effective structure that is using the reluctance principle to generate torque. However, these machines are still not widely adopted in industry [3], mainly because of their design challenges and complex control [4]. This paper introduces a novel, fast and accurate, approach towards the design of the SynRel machines, that can be adopted as a preliminary sizing tool.

The first step for a machine design is to roughly estimate the size of the main components. Usually standard text-books approach for machine sizing is used, based on the generalized torque relation for common cylindrical machines. The torque relation is derived as a function of the machine's volume and magnetic field energy in the machine's air gap [5]. Various

\footnotetext{
${ }^{1}$ Manuscript received March 28, 2020; revised May 13, 2020, June 14, 2020; accepted July 18, 2020. This work was supported in part by the Natural Science Foundation of China via the project with code 51850410515.

M. Murataliyev, M. Degano, G. Buticchi, H. Zhang and M. Galea are with Key Laboratory of More Electric Aircraft Technology of Zhejiang Province and University of Nottingham Ningbo Campus (UNNC), (email: mukhammed.murataliyev@nottingham.ac.uk

michele.degano@nottingham.ac.uk, giampaolo.buticchi@nottingham.edu.cn, he.zhang@nottingham.edu.cn, michael.galea@nottingham.ac.uk, )
}

adaptations of this sizing technique have been discussed in literature [2], [4], [7]. The most common approach is traditionally based around the relationship between the volume and the two main constraints of any machine, namely the magnetic limit and the thermal limit [8], [9].

The approach was modified and extended for Synchronous Reluctance (SynRel) machines in [10], where the preliminary sizing approach considers the rotor geometry, which is critical for reluctance machine. It was justified by proving a nonlinearity of saliency ratio with respect to the rotor radius [10], [11]. In [12], [13], the generalized scaling method based on the homothety concept was described for Induction Machines (IM). This scaling approach is another way of considering the sizing of an electrical machine. In [9], this approach was implemented for a wide range of IMs and has defined a set of generalized equations for the machine's power as a function of weight and size, using a heuristic-based statistical method. In this paper, the homothety principle is applied for the first time to SynRel machines.

It is well known [6], [10] that the main electromagnetic sizing equations for an electrical machine are related to the torque. Therefore, this paper will focus on the electromagnetic correlations of the scaled geometries, and their effect on the torque. One of the key features of SynRel is the magnetic anisotropy of the rotor to produce torque. Because of the absence of any rotor excitation, then considering the magnetic saturation of both stator and rotor, at the preliminary design stage, presents the main challenge, which has been addressed in this work. The analytical method proposed in [6], which includes the air gap function approach and saturation coefficients, is used to derive the dependency of torque with respect to the size of the scaled machines. These are derived using an iterative method applied to the equivalent magnetic circuits of the scaled geometries [10], [14]. Furthermore, the well-known maximum torque per ampere (MTPA) vector, which in fact is a function of saturation [15], will be evaluated.

The paper is structured as follows: at first three reference machine geometries are defined, labelled as M1, M2 and M3, based on existing designs. These have different combinations

D. Prystupa, W. Shuo and H. Zhang are with the Nottingham Electrification Center (NEC), Yuyao, Zhejiang Province, China (email: dmytro.prystupa@nottingham.edu.cn, wangshuo-27@163.com)

M. Di Nardo, M. Degano, C. Gerada and M. Galea are with PEMC Group, University of Nottingham, Nottingham, UK.(email: mauro.dinardo4@nottingham.ac.uk, chris.gerada@nottingham.ac.uk) 
of stator and rotor geometrical parameters. Using the analytical tool, presented in Section II, a wide range of the scaled machines of each reference geometries has been analyzed and their electromagnetic performance calculated, in Section III. Finite Element (FE) simulations are used to validate the analytically calculated data and proposed theory for 9 scaled geometries, in Section IV. In Section V, the analytical model was then used for the general scaling derivation of the main sizing equations. The experimental validation of the proposed sizing equation is presented in Section VI two SynRel scaled machines designed according to this method and prototyped.

\section{ANALYTICAL MODELING OF SYNREL:}

The electromagnetic performance of each scaled motors can be evaluated as discussed in [10], where the generalized sizing approach was derived for reluctance machines using a wellknown $d-q$ reference frame torque equation:

$$
T_{e m}=\frac{3}{2} p\left(L_{d}-L_{q}\right) i_{d} i_{q}
$$

Where $p$ represents the number of pole pairs, $L_{d}$ and $L_{q}$ are the direct and quadrature inductances, respectively; and $i_{d}, i_{q}$ are the direct and quadrature currents flowing in the stator windings. In (1), the main electromagnetic variables are the direct and quadrature axis inductances. In a reluctance motor within a $d-q$ - reference frame, the $d$ - axis is the path of least reluctance and the $q$-axis is the path of greater reluctance; reflecting into unequal inductances, dependent on the rotor position.

In [10] and [11], the main SynRel parameters studied were the magnetizing coefficients $K_{d m}, K_{q m}$ which are related to the salient nature of reluctance machines:

$$
\begin{aligned}
& K_{d m}=\frac{B_{1 d}}{B_{1}}=\frac{L_{d m}}{L_{m}} \\
& K_{q m}=\frac{B_{1 q}}{B_{1}}=\frac{L_{q m}}{L_{m}}
\end{aligned}
$$

As shown in equations (2) and (3), $B_{l}$ represents the fundamental component of the air-gap flux density for a uniform air-gap machine (no saliency) and $B_{l d}, B_{l q}$ are set to be the fundamental components of $d$ and $q$ excited axes. Hence, ratios of fundamental flux density components are defined as magnetizing coefficients. The latter, in (2) and (3), also represent ratios of magnetizing inductances, where $L_{m}$ is a magnetizing inductance of a non-salient rotor and $L_{d m}, L_{q m}$ are direct and quadrature magnetizing inductances of a salient rotor [16]. Consequently, using (2) and (3) as derived in [10], the saliency ratio $\xi$ can then be defined as shown in (4), where $L_{l}$ represents the leakage inductance:

$$
\begin{aligned}
& \xi=\frac{L_{d}}{L_{q}}=\frac{L_{d m}+L_{l}}{L_{q m}+L_{l}} \\
& =\frac{L_{m} K_{d m}+L_{l}}{L_{m} K_{q m}+L_{l}} \sim \frac{L_{m} K_{d m}+L_{m} K_{q m}}{2 L_{m} K_{q m}}
\end{aligned}
$$

According to equation (1), the electromagnetic torque is directly proportional to the difference between $L_{d}$ and $L_{q}$. Based on the equations (1) - (4), it can be concluded that the main electromagnetic parameters of SynRel machines are direct and quadrature magnetizing coefficient. Therefore, $K_{d m}, K_{q m}$ have to be derived and evaluated as functions of the main machine dimensions, in order to predict a performance of a $n$-scaled machine geometry $M_{n}$.

\section{A. Magnetizing coefficients:}

One of the fastest and most accurate approaches to estimate magnetizing coefficients for a given machine geometry is the air-gap function approach [10], [11]. The air gap function approach is used to analyze the magnetic conductivity throughout the periphery of the air gap of a cylindrical machine. Mainly, this approach focuses for both stator and rotor slotting effect on the air gap flux density distribution [17] [18]. The air gap function approach considers only the slotting effect, thus neglecting the iron saturation. For the following derivation of magnetizing coefficients, the permeability of iron is assumed to be infinite.

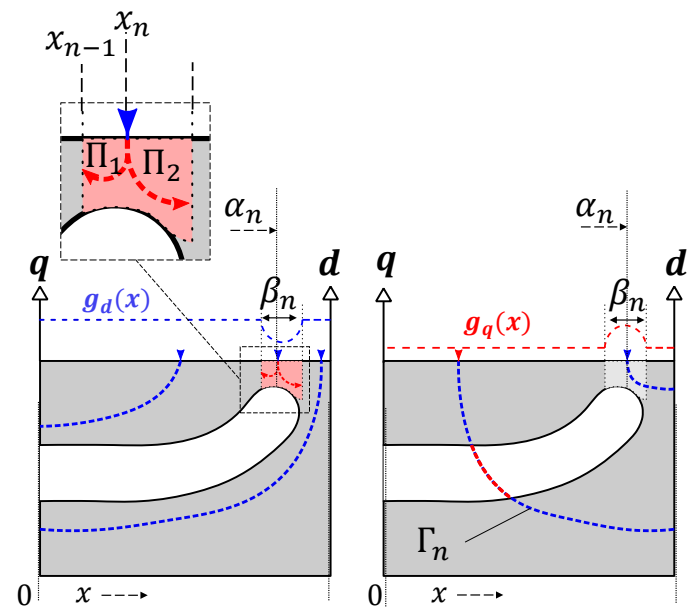

Fig. 1. Sketch of d-axis (on the left) and q-axis (on the right) flux paths. The rotor barrier slotting effect is highlighted.

Fig. 1 presents a sketch of $d$-axis and q-axis excited rotors. Using the air gap function approach, the same function with a phase lag of $45^{\circ}$ for 4-pole can be derived for the $d$-axis and $q$ axis rotor excitation. Here it is important to define the angular span of the barrier $n$ as $\alpha_{n}$ and the $n_{t h}$ barrier's opening angular thickness $\beta_{n}$. The barrier ribs are highlighted for $d$-axis rotor excitation. Where the flux paths $\Pi_{1}$ and $\Pi_{2}$ are the flux paths that pass through the saturated ribs.

In case of $d$-axis excitation the barrier openings are considered as regions with a very low magnetic conductivity, as the field is excited in their direction. The infinite slotting approach, which was derived in [18], is used for this case, as shown in Fig. 1, where idealized magnetic flux lines $\Pi_{1}$ and $\Pi_{2}$ are assumed to be equal to quarter circumference and can be derived using rotor radius $R_{r o}$ and angle expressed in polar coordinates $(x)$. The total flux paths length at the "infinite slot" can be estimated by using the parallel paths derivation as (5):

$$
\Pi_{1} \| \Pi_{2}=\frac{\pi R_{r o} \sin \left(\frac{x_{n-1}}{2}\right) \sin \left(\frac{x_{n}-x_{n-1}}{2}-\frac{x_{n-1}}{2}\right)}{\sin \left(\frac{x_{n-1}}{2}\right)+\sin \left(\frac{x_{n}-x_{n-1}}{2}-\frac{x_{n-1}}{2}\right)}
$$

Where $x_{n-1}$ and $x_{n}$ are the two consecutive angular points considered as highlighted in Fig. 1.

In case of $q$-axis excitation the barriers openings are considered magnetically conductive due to iron ribs. The $q$-axis 
air gap function should include an extra reluctance component due to insulation barriers, in this case air. Therefore, it increases with the air thickness of a flux path. The extra path can be derived as a quarter circumference of a circle as shown in Fig. 1 , where the highlighted red path represents an insulation thickness. Hence, it can be derived as a function of shaft and rotor radiuses as:

$$
\begin{gathered}
R_{\Gamma \mathrm{n}}=\frac{\left(R_{r o}-R_{s h}\right) \Delta \alpha_{n} \pi}{4} \\
\Gamma_{n} * k_{\text {air }}=\left[\frac{\left(R_{r o}-R_{s h}\right) \Delta \alpha_{n} \pi}{4}\right] \frac{\pi}{2} * k_{\text {air }}
\end{gathered}
$$

Where $k_{\text {air }}$ is the total insulation ratio, $\Delta \alpha$ is the angle span between $n^{\text {th }}$ and $(n+1)^{\text {th }}$ barriers.

Using the equations (5) - (7) and referring to Fig. 1, the general air gap functions can be derived for the $d$ and $q$ axes into (8) and (9).

$$
\begin{gathered}
g_{d}(x)=\left\{\begin{array}{cc}
0, & 0<x<\alpha_{n}-\frac{\beta_{n}}{2} \\
\Pi_{1} \| \Pi_{2}, & \alpha_{n}-\frac{\beta_{n}}{2}<x<\alpha_{n}+\frac{\beta_{n}}{2} \\
0, & \alpha_{n}+\frac{\beta_{n}}{2}<x<\frac{\pi}{4}
\end{array}\right. \\
g_{q}(x)=\left\{\begin{array}{cc}
k_{\text {air }} \cdot \Gamma_{\mathrm{n}}, & 0<x<\alpha_{n}-\frac{\beta_{n}}{2} \\
0, & \alpha_{n}-\frac{\beta_{n}}{2}<x<\alpha_{n}+\frac{\beta_{n}}{2} \\
k_{\text {air }} \cdot \Gamma_{\mathrm{n}}, & \alpha_{n}+\frac{\beta_{n}}{2}<x<\frac{\pi}{4}
\end{array}\right.
\end{gathered}
$$

Using the analytical method described above, then magnetizing coefficients can be described by (10) and (11), where $g(x)$ is a uniform air gap function for a non-salient geometry, and the parameters $g_{d}(x)$ and $g_{q}(x)$ are the air gap functions with respect to direct and quadrature axes excitations of the rotor considering rotor slotting.

$$
\begin{aligned}
& K_{d m}=\frac{4}{\tau_{p}} \int_{0}^{\tau / 2} \frac{g(x)}{g_{d}(x)} \cos ^{2}\left(\frac{\pi x}{\tau_{p}}\right) d x \\
& K_{q m}=\frac{4}{\tau_{p}} \int_{0}^{\tau / 2} \frac{g(x)}{g_{q}(x)} \cos ^{2}\left(\frac{\pi x}{\tau_{p}}\right) d x
\end{aligned}
$$

Where $\tau_{p}$ is the pole pitch.

Based on equations (6) - (11) and Fig. 1, the main rotor's geometrical parameters that affect the magnetizing coefficients are the insulation ratio $k_{\text {air }}$, the rotor $n^{\text {th }}$ barrier angular parameters: $\alpha_{n}$ barrier span, $\beta_{n}$ barrier opening angle.

In the context of scaling, both $K_{d m}$ and $K_{q m}$ are a function of rotor radius $R_{r o}$.

\section{B. Saturation model:}

Based on (1) - (11) the unsaturated saliency ratio is a pure geometrical parameter. However, $d-q$ axes inductances (4) are not constant for different values of stator current due to the nonlinear magnetic property of the stator and rotor iron.

SynRel machines have an unequal magnetic conductivity alongside the air gap and at different rotor positions, this will saturate at different rate. The derived magnetizing coefficients (10) and (11) are the values that quantify the magnetic conductivity for direct and quadrature axes, thus the total air gap flux density, which is dependent on the excitation angle $\alpha^{e}$. This can be expressed as given by (12), where $B_{d q}$ is a fundamental air gap flux density, and $B_{l}$ is a fundamental air gap flux density of a uniform air gap machine without saliency:

$$
B_{d q}=B_{1} \cdot\left(K_{d m} \cos \left(\alpha^{e}\right)+K_{q m} \sin \left(\alpha^{e}\right)\right)
$$

The magnetic circuit can be built considering 5 main reluctances, as shown in Fig. 2, where $R_{t 1}$ and $R_{t 2}$ are the stator tooth reluctances, $R_{c}$ the stator back iron reluctance, $R_{g}$ is the air gap reluctance. $R_{r i}$ and $R_{r a}$ are the rotor iron and insulation layer reluctances, respectively. The rotor reluctances can be estimated using the flux path length in a similar way as presented in (6) and (7), referring to the average thickness of the rotor. In addition, this is also considering the current angle $\alpha^{e}$ as given by (13) - (14).

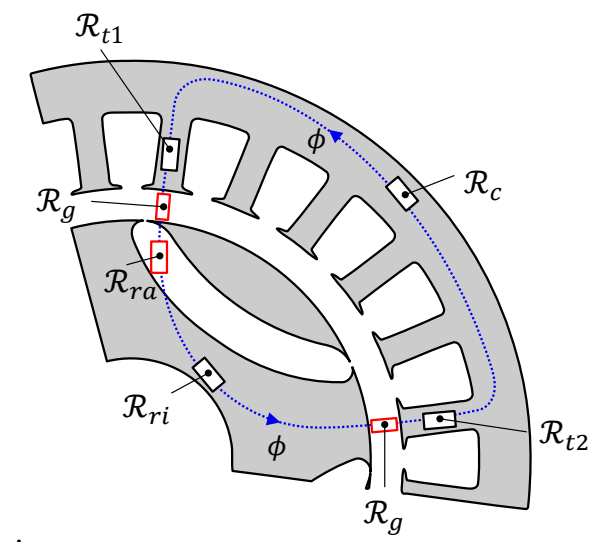

Fig. 2. SynRel magnetic circuit with highlighted reluctances.

$$
\begin{gathered}
\Gamma_{\text {iron }}=\left[\frac{R_{\text {ro }}-R_{s h}}{4}\right] \frac{\pi}{2}\left(1-k_{\text {air }} * \cos \left(\alpha^{e}\right)\right) \\
\Gamma_{\text {air }}=\left[\frac{R_{\text {ro }}-R_{s h}}{2}\right] \frac{\pi}{2} * k_{\text {air }} \sin \left(\alpha^{e}\right)
\end{gathered}
$$

The total reluctance of the rotor can be estimated as:

$$
\mathcal{R}_{r}=\frac{\Gamma_{\text {iron }}}{\mu_{r} A_{r}}+\frac{\Gamma_{\text {air }}}{\mu_{\text {air }} A_{r}}
$$

The rest of the reluctances can be modelled in a conventional way based on the stator geometry presented in [10].

Based on all the above it can be said that the flux through the magnetic circuit is function of $k_{\text {air }}$ and $\alpha^{e}$, and can be described by (16).

$$
\phi\left(\alpha^{e}, k_{\text {air }}\right) \sim \frac{m m f_{s 1}}{\mathcal{R}_{s c}+2 \mathcal{R}_{g}+\mathcal{R}_{t 1}+\mathcal{R}_{t 2}+\mathcal{R}_{r a}+\mathcal{R}_{r i}}
$$

In summary, $\phi$ and $m m f_{s l}$ can be derived using (13) - (16). One of the common ways to express magnetic saturation is to derive a saturation coefficient. This can be defined as a ratio of the fundamental of total mmfs of the magnetic circuit and the fundamental of the air gap mmf [19], [20]. The saturation factors of the direct and quadrature inductances can be derived as (17) - (18), where $m m f_{s l}$ - is the magneto motive force fundamental of the considered magnetic circuit, and $m m f_{g d}$ and $m m f_{g q}$ are direct and quadrature fundamental magneto motive forces at the air gap. 


$$
\begin{aligned}
K_{s d} & \sim \frac{m m f_{s 1}}{2 m m f_{g d}} \\
K_{s q} & \sim \frac{m m f_{s 1}}{2 m m f_{g q}}
\end{aligned}
$$

Whereas $m m f_{g d}$ and $m m f_{g q}$ can be derived using (12) as (19) $-(20)$ :

$$
\begin{aligned}
2 m m f_{g d} & =\frac{2 g B_{1} K_{d m}}{\mu_{0}} \cos \left(\alpha^{e}\right) \\
2 m m f_{g q} & =\frac{2 g B_{1} K_{q m}}{\mu_{0}} \sin \left(\alpha^{e}\right)
\end{aligned}
$$

The iterative method can be used to solve the magnetic circuit (16) to derive (17) - (20) with the respect to the main air gap flux density equation (12). This method was extensively studied in [20] and [10]. The flowchart of the saturation modeling method is described in Fig. 3, where $B_{t}$ is the average flux density at the stator tooth, $B_{c}$ is the average flux density at the stator back iron and $B_{c r}$ is the average flux density at the rotor core.

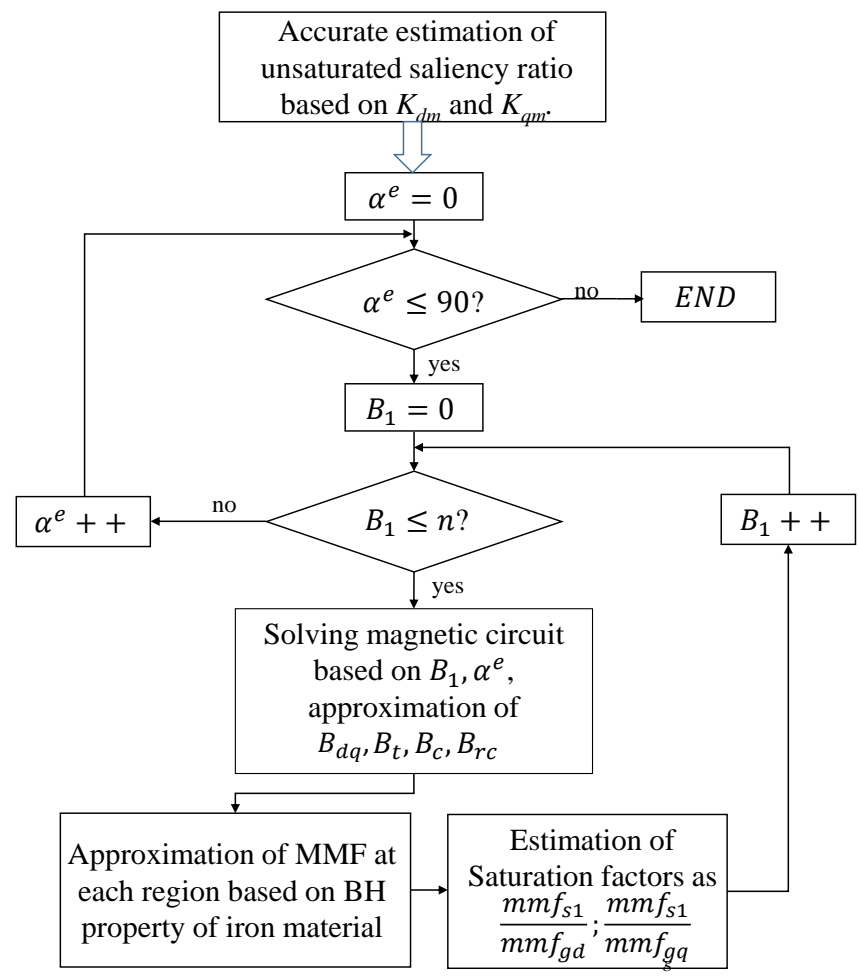

Fig. 3. Flow chart of the saturation modeling [10].

Using the method described the direct and quadrature inductances can be rewritten as (21) and (22):

$$
\begin{gathered}
L_{d}=\frac{L_{m} K_{d m}}{\left(1+K_{s d}\right)}+\frac{L_{m} K_{q m}}{\left(1+K_{s q}\right)} \\
L_{q}=2 \frac{L_{m} K_{q m}}{\left(1+K_{s q}\right)}
\end{gathered}
$$

For 3-phase machines, the magnetizing inductance $L_{m}$ is calculated as shown in (23), where $R_{r o}$ is the rotor diameter, $L_{s t k}$ is the stack length, $q$ is the number of slots per pole per phase, $g$ is the air gap length, $\mu_{0}$ is the relative permeability of air. $K_{w 1}$ is the winding factor. In (7), the parameters $R_{r o}$ and $L_{s t k}$ are the variables of interest as these determine the size of the machine.

$$
L_{m}=6 \mu_{0} R_{\text {ro }} L_{s t k} \frac{\left(q K_{w 1} n_{s}\right)^{2}}{g}
$$

The equation of the magnetizing coefficients (10) - (11) which are dependent on the flux paths length (5) - (7) are clearly the function of rotor radius $R_{r o}$. Therefore, it will affect the saturation rate of the scaled machine (12) - (20). The equations (1), (21) - (22) are functions of both $R_{r o}$ and $L_{s t k}$.

Based on the analytical approach described in previous chapter the machines magnetic behavior can be studied as function of radial scaling, by varying $R_{r o}$ and axial scaling, by varying $L_{s t k}$. In order to relate $R_{r o}$ and $L_{s t k}$, the aspect ratio $\gamma$ can be introduced as (24):

$$
\gamma=\frac{L_{s t k}}{2 R_{r o}}
$$

\section{The PROPOSED SCALING PRINCIPLE}

In mathematics the homothety is a transformation of an affine space determined by a point ' $O$ ', which usually is its center, and a nonzero coefficient of scaling [21], [22].

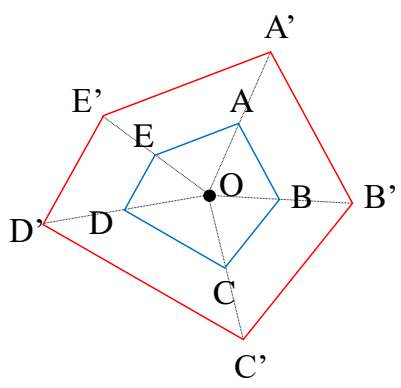

Fig. 4. Homothety example.

The concept can be simply represented as shown in Fig. 4, where two similar figures are related by a homothetic transformation with respect to their center $O$.

As discussed in [12] and [13], the main idea of homothetic scaling in machine design is to derive a scaling factor $s_{n}$ for some key machine parameters. For example, the torque $T_{n}$ that characterize the motor $M_{n}$ in the form shown in (25), where $T_{n}$ is a torque of an $n$-scaled machine, $s_{n}$ is the scaling coefficient that can be derived using a regression method or using other appropriate statistical technique, $R_{n r o}$ is the rotor radius of the $n$ scaled machine and $\gamma_{n}$ is the aspect ratio of $M_{n}$.

$$
T_{n}\left(R_{\text {nro }}, \gamma_{n}\right)=s_{n} T_{\text {ref }}\left(R_{\text {roref }}, \gamma_{\text {ref }}\right)
$$

In order to derive the scaling coefficients in (25), a reference machine $M_{\text {ref }}$ has to be radially or axially scaled, therefore varying $R_{\text {roref }}$ and $\gamma_{\text {ref }}$, and resulting scaled geometries can be evaluated using analytical model presented previously.

\section{A. Reference Machines:}

In this section, the three reference SynRel geometries, namely M1, M2 and M3, are defined in detail for both stator and rotor with dimensions reported in Table I and Table II. These have been selected to cover different machine frames, typically in the low to medium power range. The general stator geometry for the reference motors is shown in Fig. 5. 


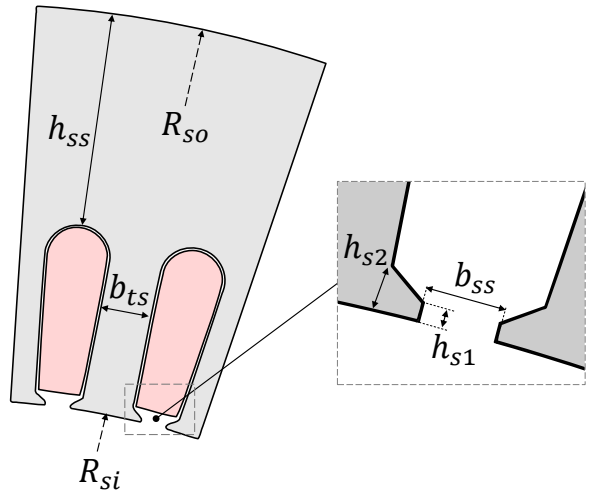

Fig. 5. Sketch of stator geometrical parameters.

Through the geometrical parameters shown in Fig. 6 a comprehensive parametrization of the flux barriers can be achieved [23], [24].

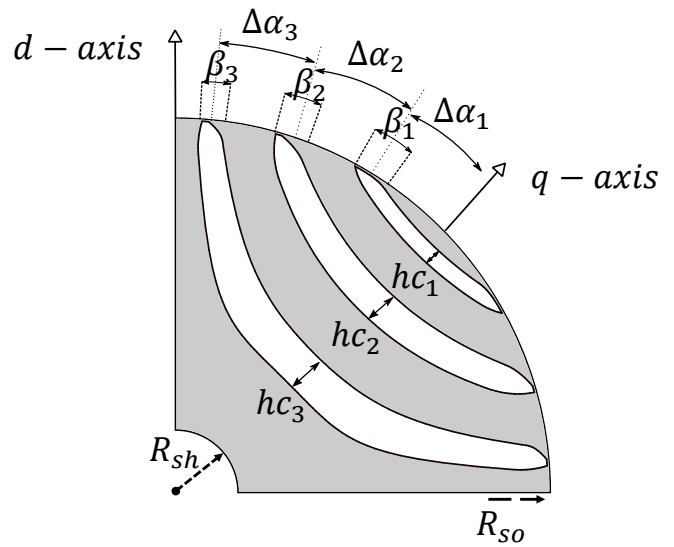

Fig. 6. Quarter of geometry for anisotropic type rotor with 3 - barriers and 4-pole configuration. Based on $\Delta \alpha_{k}$ (per unit value of $\alpha$ ) and $h c_{k}$ (per unit value of barrier thickness).

Table I. Reference machines' main dimensions

\begin{tabular}{|c|c|c|c|c|}
\hline \multirow{2}{*}{ Symbol } & \multirow{2}{*}{ Parameter } & \multicolumn{3}{|c|}{ Quantity } \\
\hline & & M1 & M2 & M3 \\
\hline$N_{s}$ & $\begin{array}{l}\text { Number of } \\
\text { slots }\end{array}$ & 48 & 48 & 72 \\
\hline$R_{\text {so }}$ & $\begin{array}{l}\text { Stator outer } \\
\quad \text { radius }\end{array}$ & $200 \mathrm{~mm}$ & $130 \mathrm{~mm}$ & $260 \mathrm{~mm}$ \\
\hline$R_{s i}$ & $\begin{array}{l}\text { Stator inner } \\
\text { radius }\end{array}$ & $130 \mathrm{~mm}$ & $85 \mathrm{~mm}$ & $175 \mathrm{~mm}$ \\
\hline$g$ & $\begin{array}{l}\text { Air gap } \\
\text { thickness }\end{array}$ & $1 \mathrm{~mm}$ & $0.5 \mathrm{~mm}$ & $1.1 \mathrm{~mm}$ \\
\hline$R_{r o}$ & $\begin{array}{l}\text { Rotor outer } \\
\text { radius }\end{array}$ & $129 \mathrm{~mm}$ & $84.5 \mathrm{~mm}$ & $173.9 \mathrm{~mm}$ \\
\hline$h_{s s}$ & $\begin{array}{l}\text { Stator Back } \\
\quad \text { iron }\end{array}$ & $37.9 \mathrm{~mm}$ & $22.8 \mathrm{~mm}$ & $42.6 \mathrm{~mm}$ \\
\hline$b_{t s}$ & $\begin{array}{l}\text { Stator Tooth } \\
\text { width }\end{array}$ & $9.3 \mathrm{~mm}$ & $5.16 \mathrm{~mm}$ & $7.1 \mathrm{~mm}$ \\
\hline$b_{s s}$ & $\begin{array}{l}\text { Stator Slot } \\
\text { opening }\end{array}$ & $4 \mathrm{~mm}$ & $3.5 \mathrm{~mm}$ & $4.2 \mathrm{~mm}$ \\
\hline$h_{s 1}$ & $\begin{array}{l}\text { Stator Slot } \\
\text { opening } \\
\text { height }\end{array}$ & $1 \mathrm{~mm}$ & $0.8 \mathrm{~mm}$ & $1.5 \mathrm{~mm}$ \\
\hline$h_{s 2}$ & Wedge height & $1.4 \mathrm{~mm}$ & $1.6 \mathrm{~mm}$ & $2.65 \mathrm{~mm}$ \\
\hline$L_{s t k}$ & Stack Length & $205 \mathrm{~mm}$ & $240 \mathrm{~mm}$ & $390 \mathrm{~mm}$ \\
\hline
\end{tabular}

These are drawn using the Joukowski air-flow potential equation [10], . All the rotor parameters of interest are highlighted in Fig. 6. The total insulation ratio $k_{\text {air }}$ can be derived as an average value of $h c_{k}$ as described in [10]. The rotor barriers geometrical parameters, for the reference machines, are reported in Table II.

\begin{tabular}{ccccc}
\multicolumn{5}{c}{ Table II. Reference rotors dimensions } \\
\hline \hline \multirow{2}{*}{ Symbol } & Parameter & \multicolumn{3}{c}{ Quantity } \\
\cline { 3 - 5 } & & M1 & M2 & M3 \\
\hline \multirow{2}{*}{$k$} & $\begin{array}{c}\text { Number of } \\
\text { barriers }\end{array}$ & 3 & 4 & 3 \\
$\Delta \alpha_{1}$ & $\begin{array}{c}\text { Angular bar 1 } \\
\text { span } \\
\Delta \alpha_{2}\end{array}$ & $14.59^{\circ}$ & $10.91^{\circ}$ & $12.39^{\circ}$ \\
& $\begin{array}{c}\text { Angular bar } 2 \\
\text { span }\end{array}$ & $14.28^{\circ}$ & $9.24^{\circ}$ & $14.77^{\circ}$ \\
$\Delta \alpha_{3}$ & $\begin{array}{c}\text { Angular bar 3 } \\
\text { span }\end{array}$ & $11.52^{\circ}$ & $9.68^{\circ}$ & $12.28^{\circ}$ \\
$\Delta \alpha_{4}$ & $\begin{array}{c}\text { Angular bar 4 } \\
\text { span }\end{array}$ & - & $10.09^{\circ}$ & - \\
$k_{\text {air }}$ & Insulation ratio & 0.37 & 0.473 & 0.465 \\
\hline \hline
\end{tabular}

\section{B. Radial geometry scaling assumptions:}

Using the reference geometries presented in Table I and Table II the appropriate geometrical scaling procedure should be defined. For the further performance evaluation, the air gap will be kept constant, i.e. for M1 $g=1 \mathrm{~mm}$, therefore for any M1 scaled geometry the air gap will be the same. The geometry scaling coefficients are defined as shown in equations (26) and (27), where $R_{s i-r e f}$ and $R_{s i-n}$ are the stator inner radiuses of the reference machines and the scaled machines, respectively. Also, $S_{s i}$ and $S_{r o}$ are the scaling coefficients for any stator and any rotor geometrical parameter, respectively.:

$$
\begin{gathered}
S_{s i}=\frac{R_{s i-n}}{R_{s i-r e f}} \\
S_{r o}=\frac{R_{s i-n}-g}{R_{s i-r e f}-g}
\end{gathered}
$$

The angular parameters, such as angular barriers span are kept constant for any derived geometry, therefore they are not subject of scaling.

\section{Effect of scaling on magnetizing coefficients:}

To study the effect of scaling on $K_{d m}, K_{q m}$, consider the reference geometries M1, M2 and M3. Starting from these a range of geometries has been scaled according to the rules described by (26) and (27). 

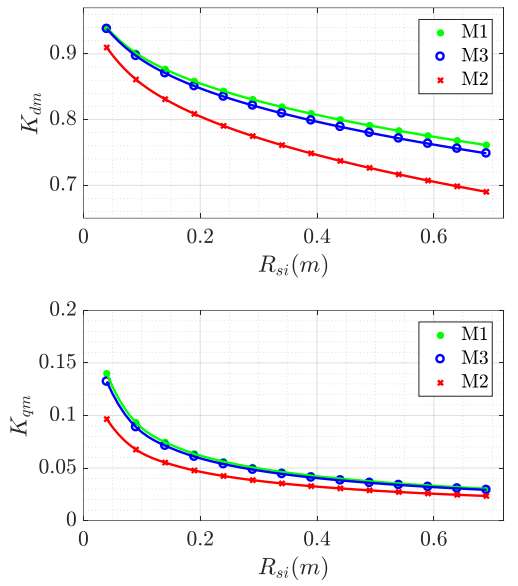

Fig. 7. Magnetizing coefficient $K_{d m}$ and $K_{q m}$ as a function of stator inner radius for $\mathrm{M} 1, \mathrm{M} 2$ and $\mathrm{M} 3$ geometries.

As can be observed from Fig. 7, both $K_{d m}$ and $K_{q m}$ decrease with the stator inner radius. However, the behavior of $K_{q m}$ differs from $K_{d m}$ significantly with the decrease $R_{s i}$, i.e as shown on Fig. 7 for M2 $K_{d m}$ and $K_{q m}$ drop by $\sim 24 \%$ and $\sim 71 \%$ respectively. As presented in Table II, $k_{a i r}$ for M1 is significantly lower compared to M2, which results in higher magnetizing coefficient as the air paths length are decreased (6) $-(7)$.

In summary the magnetizing coefficients tend to decrease with the stator inner diameter at fixed air gap. As the $K_{d m}$ and $K_{q m}$ change at different rate with respect to $R_{s i}$, it can be said that smaller $R_{s i}$ will have lower saliency and hence lower torque capability. Using the magnetizing coefficients calculated above, the saturation model can be derived, which will be discussed in the following subsection.

Considering (10) - (11), the magnetizing coefficients do not depend on the radial scaling. However, the inductances (21) (22) will proportionally change with respect to axial scaling, therefore the torque is changed as well (1).

\section{Effect of scaling on saturation:}

To evaluate the effect of scaling on saturation levels the reference geometries M1, M2 and M3 will be considered in the following analysis. For the modelling example the $\mathrm{BH}$ property of the silicon iron M270-50A was used. Fig. 8 presents the modelled air gap flux densities $B_{d q}$ and corresponding $m m f_{s l}$ of the magnetic circuit (Fig. 2) of M1, M2 and M3 on the fundamental air gap flux density of a nonsalient rotor $B_{1}$ and stator inner radius $R_{s i}$ plane. The air gap flux density was modelled for a wide range of scaled geometries using equation (12). The flux densities levels were calculated based on the previously derived magnetizing coefficients Fig. 7.

Fig. 8 a) is showing the lower air gap flux density $B_{d q}$ levels for M1, M2 and M3, while Fig. 8 b) is the corresponding fundamental $m m f_{s I}$ levels of the magnetic circuit at $\alpha^{e}=45^{\circ}$. In c) and d) the higher air gap flux densities and fundamental $m m f_{s 1}$ levels at $\alpha^{e}=45^{\circ}$ are highlighted, while and e) and f) are the higher air gap flux densities and $m m f_{s I}$ levels at $\alpha^{e}=60^{\circ}$.
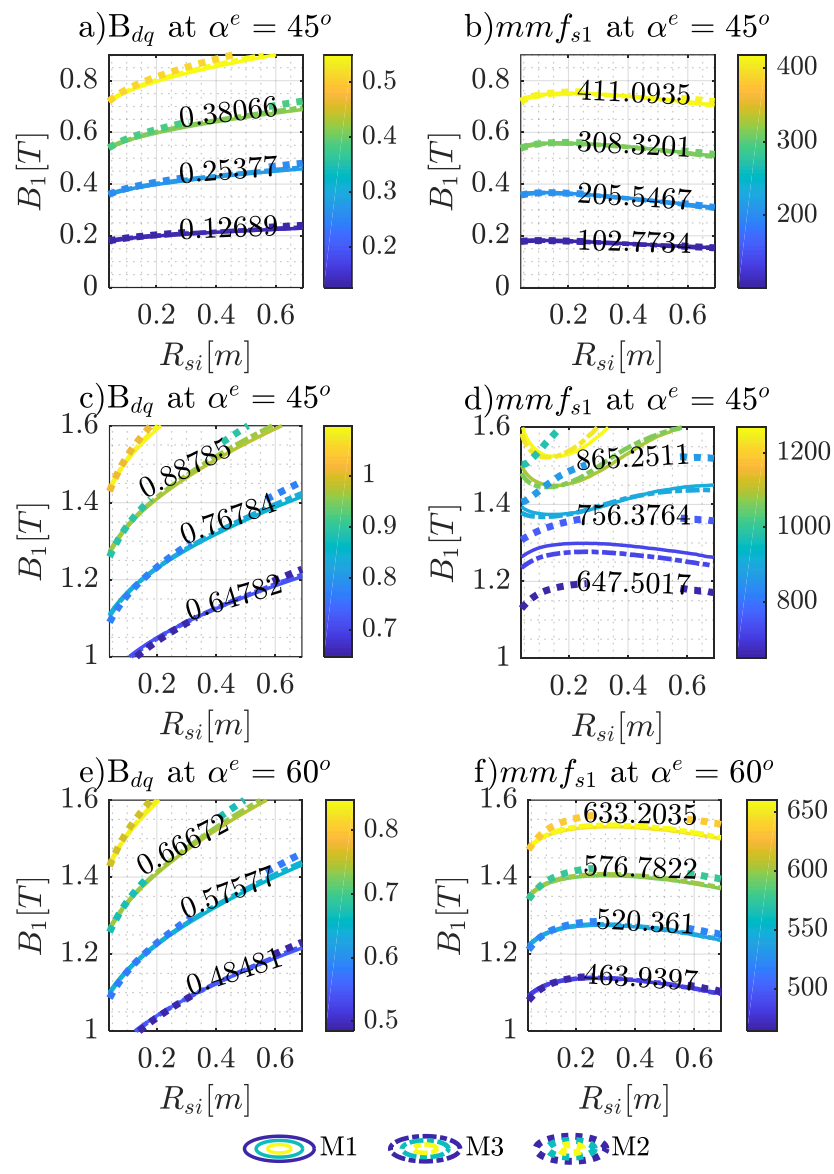

Fig. 8. Analytical model outputs: air gap flux densities and fundamental magneto motive forces for M1, M2 and M3 based on the scaled magnetizing coefficients.

As can be observed, the smaller geometries have a higher magnetic conductivity due to greater values of $K_{d m}$ and $K_{q m}$. Therefore, the corresponding air gap flux densities and magneto motive forces levels are higher. However, the values do not vary significantly with respect to $R_{s i}$. In addition, it can be noted that M1 has higher values of $m m f_{s l}$ for the corresponding flux levels, which is reflected by higher values of magnetizing coefficients (Fig. 7) and lower value of $k_{\text {air }}$. This leads to a much higher magnetic conductivity for both $d$ and $q$ axes as the rotor reluctance is reduced (13) - (16).

At higher $B_{l}$ levels the corresponding $B_{d q}$ flux densities and fundamental $m m f_{s l}$ will drop if the current angle is increased as shown Fig. 8 e) and f). As can be noted the $m m f_{s I}$ levels do not vary significantly with the increase of $R_{s i}$, hence, it can be concluded that the saturation levels do not vary as well.

Considering the axial scaling, the saturation patterns will not change. As the geometry of the rotor and stator will change in axial direction, therefore the conductor length and main reluctances, (13) - (16) will vary proportionally, whereas the flux density levels will remain unchanged.

\section{E. Correlation of MTPA for the M2 scaled geometries:}

The MTPA behavior of the scaled SynRel will be evaluated on the M2 geometry as a case study in both axial and radial scaling. Using the modelling technique described above and the 
$\mathrm{BH}$ property of the iron material, the effect of scaling on MTPA can be evaluated.

Equation (1) can be used, however since at this point the number of turns is unknown the following updated equation (28) can be used. As can be observed in (28) the number of turns can be simplified, hence:

$$
\begin{aligned}
T_{e m} & \sim 1.5 p\left[L_{d 1} \cdot\left(n_{s}\right)^{2}-L_{q 1} \cdot\left(n_{s}\right)^{2}\right] \cdot \frac{m m f_{d}}{\left(n_{s}\right)} \cdot \frac{m m f_{q}}{\left(n_{s}\right)} \\
& =1.5 p\left[L_{d 1}-L_{q 1}\right] \cdot m m f_{d} \cdot m m f_{q}
\end{aligned}
$$

Where $m m f_{d}$ and $m m f_{q}$ are the $d$-axis and $q$-axis mmfs, respectively. The main inductances values with neglected number of turns can be derived from (29) and (30) as:

$$
\begin{aligned}
& L_{d 1}=\left[\frac{K_{d m}}{\left(1+K_{s d}\right)}+\frac{K_{q m}}{\left(1+K_{s q}\right)}\right] \\
& \cdot 6 \mu_{0} R_{r o} L_{s t k} \frac{\left(q K_{w 1}\right)^{2}}{g} \\
& L_{q 1}=\left[\frac{2 K_{q m}}{\left(1+K_{s q}\right)}\right] \cdot 6 \mu_{0} R_{r o} L_{s t k} \frac{\left(q K_{w 1}\right)^{2}}{g}
\end{aligned}
$$

In equations (29) and (30), saturation factors are calculated using (17) and (18), to model the saturation, as described in Fig. 3. The calculated values of $T_{e m}$ (28) can be graphed on the $m m f_{d}$ - $m m f_{q}$ plane, as shown in Fig. 9 a) where the per unit torque variation, for different values of $m m f_{s l}$, is presented for the M2 geometry. In the following parts the torque is expressed in per unit values with reference to the rated torque. This occurs at the rated current for an MTPA angle $\alpha^{e}=60^{\circ}$. For example, considering $\mathrm{M} 2$, for stator scaling factor $S_{s i}=1$ the MTPA $\alpha^{e}=60^{\circ}$ occurs at $m m f_{s l}=2300$. Therefore p.u. torque is for M2 can be expressed as (31):

$$
T_{p u}=\frac{T\left(m m f_{s 1}, \alpha^{e}\right)}{T\left(2300,60^{\circ}\right)}
$$

In addition, the iso-torque curves on Fig. 9a) for scaled geometries, based on the scaling rules (26) and (27), are shown for different $S_{s 1}(0.3,1,3)$. As can be observed the torque behavior for all scaled geometries follows the same pattern. Therefore, it can be concluded that the MTPA vectors will have same values for all the geometries. It can be observed that torque curves for the geometry $S_{s i}=3$ have slightly lower values of MTPA vectors. This is justified by the smaller values of magnetizing coefficients $K_{d m}$ and $K_{q m}$, as shown in Fig. 7 and Fig. 8.

Fig. 9 b) presents the comparison for axially scaled geometries. As can be observed the torque increases proportionally to the aspect ratio as the $d-q$ axes inductances (28) - (30) increase. However, the torque curves follow the same patterns.
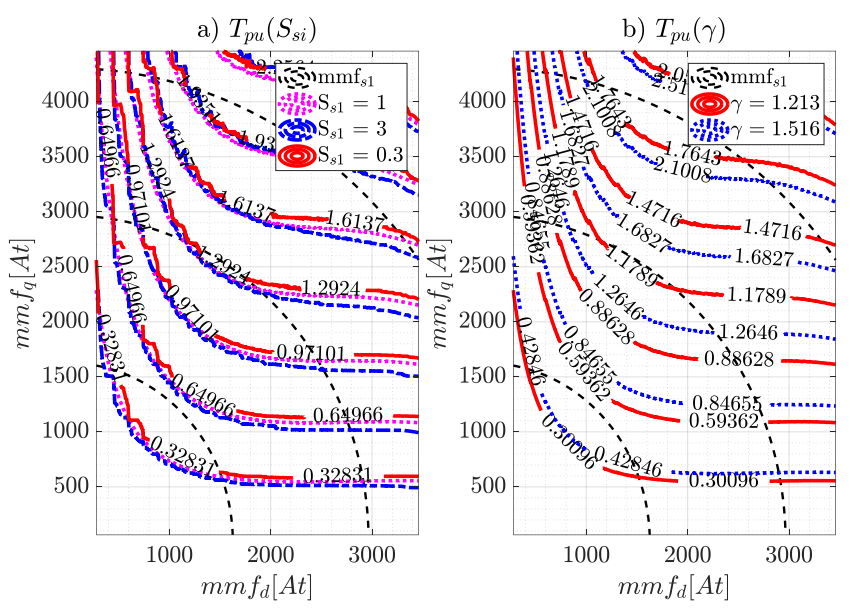

Fig. 9. M2 geometries p.u. values of torque on $m m f_{d}-m m f_{q}$ plane. a) radially scaled, b) axially scaled.

Based on all the above it can be said that any scaled geometry will approximately saturate at the same values of $m m f_{s l}$, which will result in the same MTPA current vector for the given values of Ampere-turns, $n_{s} I_{s}$. However, the radially scaled geometries will slightly deviate with respect to magnetizing coefficient (Fig. 7).

\section{F. Thermal and structural considerations}

The design of any electrical machine is a multi-disciplinary exercise, which is not only electromagnetic. Despite the proposed work is focusing on a method to analytically evaluate the magnetic behavior of SynRel machines by means of homothetic scaling, it is worth to draw some important thermal and structural considerations.

\section{1) Thermal aspects:}

As it was described in [19], the thermal behavior of the machine is mainly function of the current density, as well as conductive and convective paths, depending on the cooling system adopted. Based on the findings that were described in the previous subsection, the total current per slot remains the same for all scaled machine's family. Hence, in order to keep the same current density for all the machines, the rated current can be proportionally scaled, as the area of the slot is increased or decreased. In Table III, $A_{s l}$ is the slot area and $I_{\text {slot }}$ is the total current per slot to maintain a current density $J=3.5 \mathrm{~A} / \mathrm{mm}^{2}$, considering a slot fill factor $k_{\text {fill }}=0.4$.

As shown in Table III, following the scaling coefficients based on (26) - (27) the area of the slot is scaled by $S_{s i}{ }^{2}$.

Table III. Scaling for constant current density, geometry M1: $J=3.5 \mathrm{~mm}^{2}$ and $k_{\text {fill }}=0.4$

\begin{tabular}{ccc}
\hline \hline$S_{s i}$ & $A_{s l}$ & $I_{\text {slot }}$ \\
\hline 1 & $280.6 \mathrm{~mm}^{2}$ & $393 \mathrm{~A}$ \\
0.75 & $157.8 \mathrm{~mm}^{2}$ & $221 \mathrm{~A}$ \\
1.25 & $438.4 \mathrm{~mm}^{2}$ & $614 \mathrm{~A}$ \\
\hline \hline
\end{tabular}

\section{2) Structural aspects:}

In a SynRel motor, the sizing of both radial and tangential ribs has been investigated extensively [25], [26]. The function of the iron ribs is to retain the rotor parts together and to withstand the centrifugal force depending on the speed of the 
machine. Different structural analysis on SynRel motors are showing how to distribute the iron ribs in order to minimise their thickness while keeping the mechanical stress below the maximum tensile strength of the lamination material [27]. This is normally considering the maximum speed of the application, plus and extra overspeed percentage, depending on the safety margin desired. For example, if the scaling leads to thinner ribs the speed of the machine could be affected and needs to be assessed to guarantee the structural integrity of the rotor. On the other hand, if the scaling leads to excessively large ribs, this will affect the average torque and they will need to be adjusted based on the target speed. To the purpose of this preliminary analytical sizing, by means of the presented homothetic method, the ribs have been scaled proportionally. This is valid within certain scaling ranges and the number of ribs, their thickness and distribution will require adjustments during the refinement stage of the machine design.

\section{FE EVALUATION:}

To validate the theory proposed above, a campaign of FE simulations have been carried out for a wide range of scaled geometries of M1, M2 and M3. The simulation details are summarized in Table IV. 9 different radially scaled machines for each reference geometry were evaluated.

In order to carry out a fair evaluation, all geometries were scaled within a same range of stator inner diameter $R_{s i}$, and the scaling coefficients were derived according to (26) and (27).

The FE and analytical results have been expressed in p.u. torque maps according to equation (28) on the $S_{s i}-\alpha^{e}$ plane for scaled geometries M1, M2 and M3, as presented in Fig. 10 a) b) and c), respectively. Whereas Fig in Fig. 10 d) e) and f), the errors of analytical results with respect to FE are shown for M1, M2 and M3 respectively. As can be observed the error increses at lower $\left(\alpha^{e}<15^{\circ}\right)$ and higher $\left(\alpha^{e}>75^{\circ}\right)$ values of the excitation angle, however stays within $2.5 \%$ margin at rated $\alpha^{e}=60^{\circ}$

In Fig. 10 a) b) and c), for each reference geometry, 9 points are highlighted on each figure, which represents the peak torque of each scaled geometry simulated using FE.

Table IV. Details of FE evaluation

\begin{tabular}{|c|c|c|c|c|}
\hline \multirow{2}{*}{ Symbol } & \multirow{2}{*}{ Parameter } & \multicolumn{3}{|c|}{ Quantity } \\
\hline & & M1 & M2 & M3 \\
\hline$m m f_{s 1}$ & $\begin{array}{c}\text { Rated } \\
\text { fundamental } \\
\mathrm{MMF}_{\mathrm{s}}\end{array}$ & $\sim 3200 A t$ & $\sim 2350 \mathrm{At}$ & $\sim 2900 \mathrm{At}$ \\
\hline$\alpha_{i}^{e}$ & $\begin{array}{l}\text { Rated current } \\
\text { vector angle }\end{array}$ & & $\sim 60^{\circ}$ & \\
\hline$R_{s i}$ & $\begin{array}{l}\text { Range of } \\
\text { scaled inner } \\
\text { stator } \\
\text { radiuses }\end{array}$ & \multicolumn{3}{|c|}{$40 \mathrm{~mm} \leq R_{s i} \leq 600 \mathrm{~mm}$} \\
\hline $\begin{array}{c}\text { FEA } \\
\text { Nodes }\end{array}$ & $\begin{array}{l}\text { Average } \\
\text { number of } \\
\text { nodes per } \\
\text { simulation }\end{array}$ & \multicolumn{3}{|c|}{12000} \\
\hline
\end{tabular}
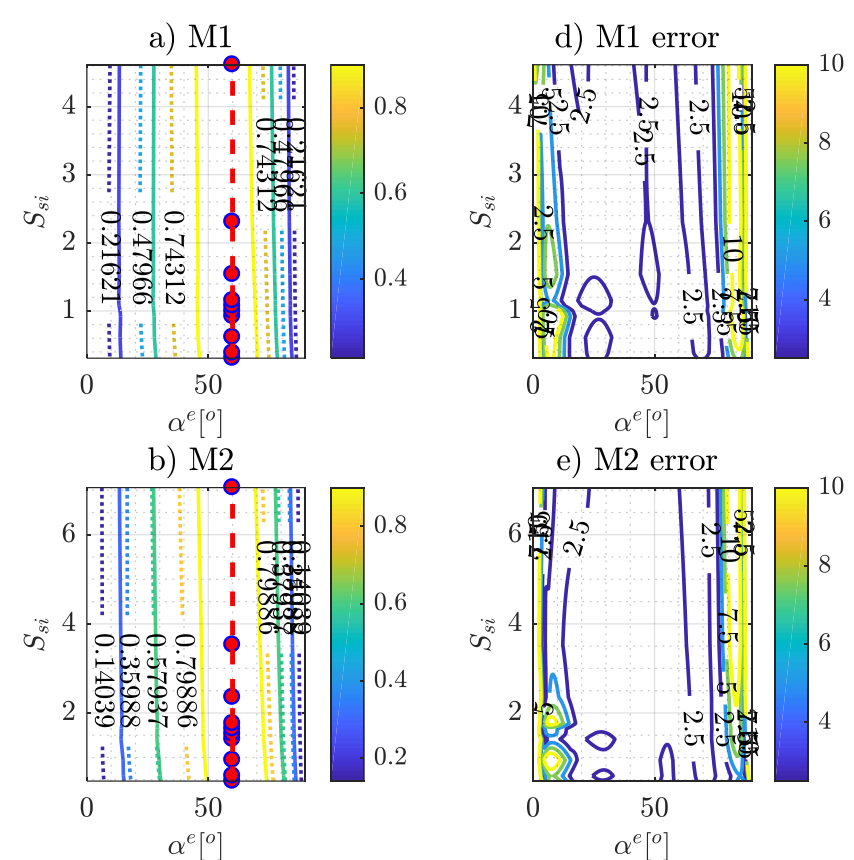

e) M2 error
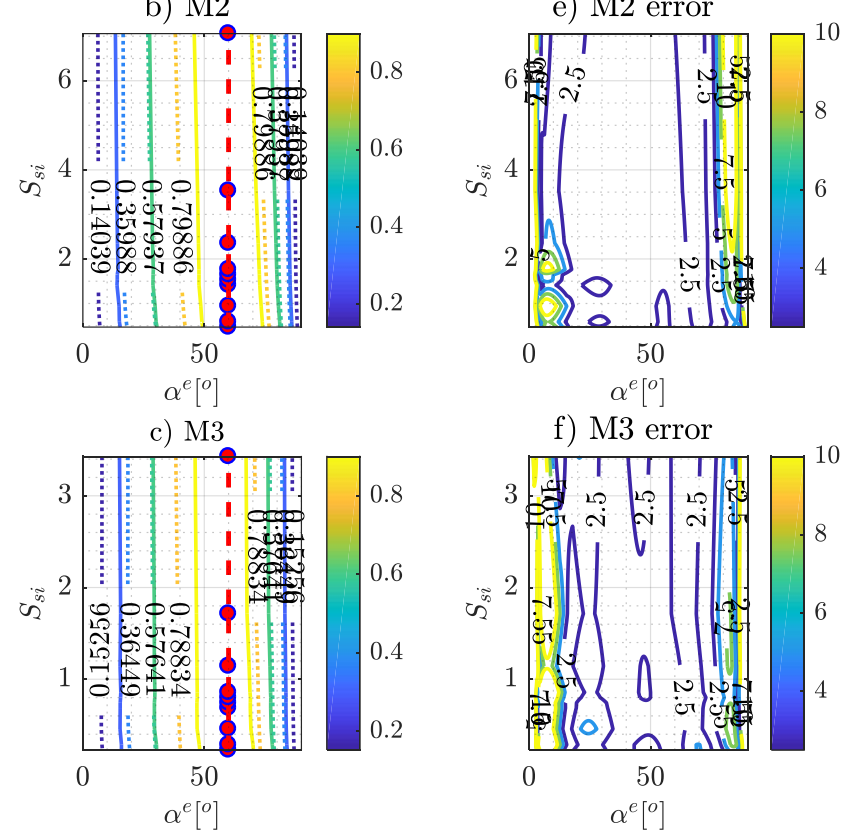

f) M3 error

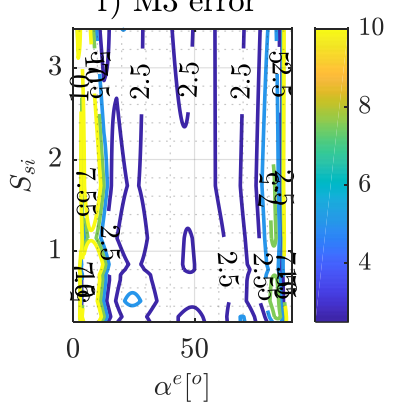

Fig. 10. Reference geometries FE simulated and analytically calculated p.u. torque on current excitation angle $\alpha^{e}$ and scaling factor $S_{s i}$ plane, a) M1 b) M2 c) M3.

As discussed previously, the MTPA angle vectors is a function of $k_{\text {air }}$. Therefore, the derived $m m f_{s l}$ have different values for each considered geometry. This is due to the different $k_{\text {air }}$ of the base machines (Table II). i.e M1 will saturate at higher $m m f_{s 1}$ values than M2 as $k_{\text {air }}$ is significantly lower.

It can be observed that the peak p.u. torque location does not vary significantly. The scaled machines with $S_{s i}<0.5$ saturate faster but the peak torque occurs at a current vector in the range of $60^{\circ}<\alpha^{e}<65^{\circ}$. This can be explained by higher values of magnetizing coefficients $K_{d m}$ and $K_{q m}$, as discussed previously. Fig. 11 shows the FE flux density plots for M2 geometries with different $S_{s i}$, at rated ampere-turns as reported in Table IV and $\alpha^{e}=60^{\circ}$. The iron flux density values are slightly different due to the higher magnetic conductivity of a smaller geometry. 


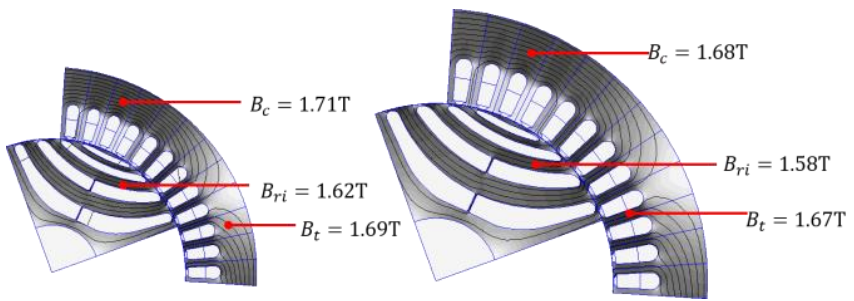

Fig. 11. FE simulated M2 geometries. On the left $\mathrm{S}_{\mathrm{si}}=1.765$, and $\mathrm{S}_{\mathrm{si}}=2.36$ on the right with highlighted flux densities.

\section{GENERAL SCALING DERIVATION:}

Using the analytically calculated data, the rated torque as function of size and volume can be derived using the regression analysis, which is a set of statistical processes for estimating the relationship between variables [28]. The following derivations will be a useful tool for evaluating size and weight of the machine that can deliver the required specifications, and quickly approximate the performance of the machine.

\section{A. Radial scaling functions:}

The power regression (PWR) technique [28], [29] was used to derive the general torque dependencies for radial scaling based on analytically calculated data. The general expression can be written as:

$$
y(x)=a x^{b}
$$

Table $\mathrm{V}$ presents the PWR coefficients for general sizing equation (32). The functions considered are the torque as a function of the stator inner radius $\boldsymbol{T}\left(\boldsymbol{R}_{s i}\right)$, the torque as a function of the machine volume $\boldsymbol{T}(\boldsymbol{V})$ and their inverse functions $\boldsymbol{R}_{s i}(\boldsymbol{T})$ and $\boldsymbol{V}(\boldsymbol{T})$.

Table V. PWR coefficients for radial scaling

\begin{tabular}{|c|c|c|c|}
\hline \multirow[t]{2}{*}{ PWR coeff. } & M1 & M2 & "M3 \\
\hline & \multicolumn{3}{|c|}{$T\left(R_{s i}\right)$} \\
\hline$a$ & 21884 & 15554 & 16823 \\
\hline \multirow[t]{2}{*}{$b$} & 2.05532 & 1.9635 & 2.0013 \\
\hline & \multicolumn{3}{|c|}{$R_{s i}(T)$} \\
\hline$a$ & 0.0076 & 0.0071 & 0.007299 \\
\hline \multirow[t]{2}{*}{$b$} & 0.4895 & 0.515 & 0.5114 \\
\hline & \multicolumn{3}{|c|}{$T(V)$} \\
\hline$a$ & 3415 & 2331 & 2631 \\
\hline \multirow[t]{2}{*}{$b$} & 0.6808 & 0.6486 & 0.6579 \\
\hline & \multicolumn{3}{|c|}{$V(T)$} \\
\hline$a$ & $6.092 * 10^{-6}$ & $6.5^{*} 10^{-6}$ & $6.311 * 10^{-6}$ \\
\hline$b$ & 1.526 & 1.54 & 1.472 \\
\hline
\end{tabular}

Fig. 12 presents sizing curves for SynRel machines for M1, M2 and M3 geometries. The plotted lines in Fig. 12 a) b) and c) d) represent the PWR functions, whereas the dots represent the 9 FE simulated data points. M1, M2 and M3 have different dimensions such as aspect ratios $\gamma=L / D$, and different air gap $g$, thus the volume and the torque varies.
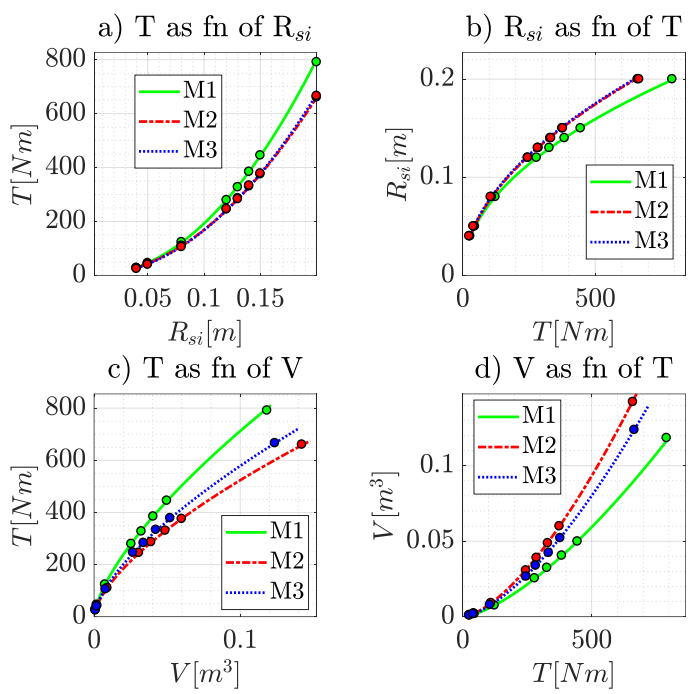

Fig. 12. M1, M2 and M3 sizing curves.

\section{B. Main sizing function:}

The polynomial regression (PLR) [28], [29] can be a suitable form for a general sizing function for both radial and axial scaling, which can be described as:

$$
T\left(R_{s i}, \gamma\right)=p_{0}+\sum_{k, j} a_{k} R_{s i}^{k}+b_{j} \gamma^{j}+c_{k, j} R_{s i}^{k} \gamma^{j}
$$

Fig. 13 presents a general sizing equation where the torque is shown as function of $R_{s i}$ and $\gamma$ (taking M2 geometry as an example). The derived coefficients of (33) are provided in the Table VI. The equations (32) and (33), based on the data from Table V and Table VI, show a good fit. (32) and can be used for quick SynRel sizing at fixed aspect ratio $\gamma$ based on Equation (33) can thus be used as a general sizing equation.

Fig. 13 also presents the FE simulated results, which was generated based on 9 different radially scaled machines. Each radially scaled geometry was axially scaled. Having 3 axially scaled machines for each radially scaled machine.

\begin{tabular}{|c|c|c|c|c|}
\hline & \multicolumn{4}{|c|}{$0^{\text {th }}$ order } \\
\hline$p_{0}$ & \multicolumn{4}{|c|}{-90.07} \\
\hline & 1st order & \multicolumn{2}{|c|}{$2^{\text {nd }}$ order } & $3^{\text {rd }}$ order \\
\hline$a_{k}$ & 1518 & \multirow{2}{*}{\multicolumn{2}{|c|}{$\begin{array}{l}-5986 \\
-39.23\end{array}$}} & 10780 \\
\hline$b_{j}$ & 94.04 & & & - \\
\hline \multirow[b]{2}{*}{$c_{k, j}$} & $c_{11}$ & $c_{21}$ & $c_{22}$ & \multirow[b]{2}{*}{ - } \\
\hline & $c_{1,1}=-935.3$ & $c_{2, l}=12640$ & 455 & \\
\hline
\end{tabular}

Table VI. PLR coefficients for $\boldsymbol{T}\left(\boldsymbol{R}_{s i}, \boldsymbol{\gamma}\right)$

\section{Iso torque curves:}

Based the homothetic identity that was shown on Fig. 9 a general function of iso p.u. torque can be expressed. Using analytically derived data p.u. torque can be derived as function of $m m f_{d}$ and $m m f_{q}$. Since there are two input variables, the PLR can be used. Therefore, the general p.u. torque expression $\boldsymbol{T}_{\boldsymbol{p u}}\left(\boldsymbol{m} \boldsymbol{m} \boldsymbol{f}_{d}, \boldsymbol{m} \boldsymbol{m} \boldsymbol{f}_{q}\right)$ can be rewritten as (34):

$$
\begin{gathered}
T_{p u}\left(m m f_{d}, m m f_{q}\right) \sim \\
\sim \sum_{k, j} a_{k} m m f_{d}^{k}+b_{j} m m f_{q}^{j}+c_{k, j} m m f_{d}^{k} m m f_{q}^{j}
\end{gathered}
$$


Where $a_{k}, b_{j}$ are the PLR coefficients. The derived function (34) can be used for any SynRel geometry using the reference $M M F$ value i.e. from Table IV for M1, M2 and M3, as the p.u. torque have a similar pattern for any scaled machine.

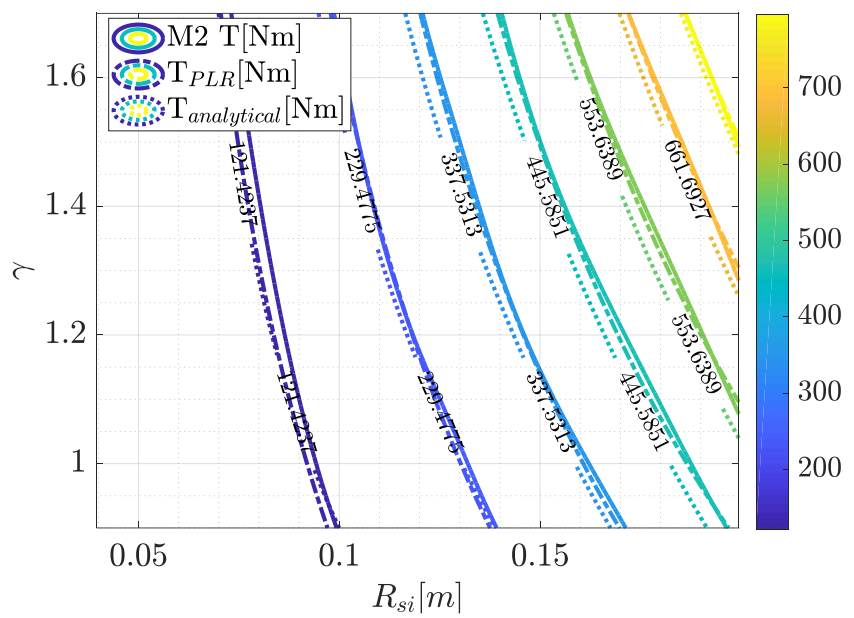

Fig. 13. $T(R s i, \gamma)$ M2 example.

\section{CASE STUdies AND EXPERIMENTAL VALIDATION:}

In order to validate the proposed scaling functions, two existing 4 poles 48 slots SynRel prototypes are considered as case studies, namely M21 and M22. A summary of their key parameters are presented in Table VI. The experimental platforms to validate the proposed analytical sizing method is shown in Fig. 14 and Fig. 15.

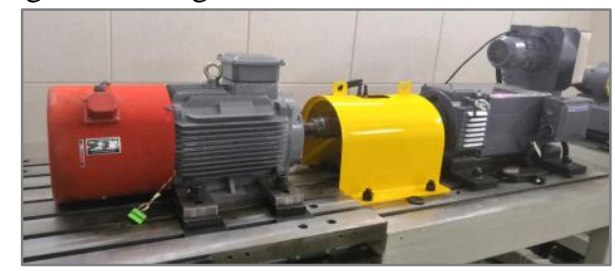

Fig. 14. Test rig: M21 SynRel motor (left hand side) and 40kW induction machine used as a load (right hand side).

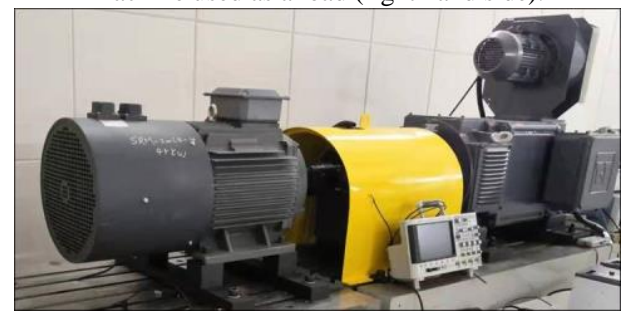

Fig. 15. Test rig: M22 SynRel motor (left hand side) and 160kW induction machine used as a load (right hand side).

On the left hand side, M21 and M22 SynRel prototypes under test are mounted on two test rig coupled with $40 \mathrm{~kW}$ and $160 \mathrm{~kW}$ induction machines on the right hand side, respectively. The motors are self-ventilated through a fan mounted on the rotor shaft. A torque meter is installed between two machines. A resolver is also mounted on the non-drive end of the SynRel motors, to provide the speed and position feedback to the drive.

Using equations (33), which is a general torque sizing equation, the rated torque for M21 and M22, can be estimated on the $T\left(R_{s i}, \gamma\right)$ plane. Fig. 16 shows the torque curves against the stator inner radius $R_{s i}$ and the aspect ratio $\gamma$. These are derived through the general torque-size relation.
Table VII. Summary of two machines scaled from M2 geometry

\begin{tabular}{cccc}
\hline \hline Symbol & Parameter & M21 & M22 \\
\hline$S_{s i}$ & Stator scaling factor & 1 & 1.2353 \\
$S_{r i}$ & Rotor scaling factor & 1 & 1.2366 \\
$R_{s i}$ & Stator inner diameter & $85 \mathrm{~mm}$ & $105 \mathrm{~mm}$ \\
$g$ & Air gap thickness & $0.5 \mathrm{~mm}$ & $0.5 \mathrm{~mm}$ \\
$L_{s t k}$ & Stack length & $205 \mathrm{~mm}$ & $235 \mathrm{~mm}$ \\
$\gamma$ & Aspect ratio & 1.213 & 1.119 \\
$N_{s}$ & Number of turns per phase & 64 turns & 64 turns \\
$I_{s}$ & Current at MTPA $\alpha^{e}=60^{\circ}$ & $56.2 \mathrm{~A}$ & $56.2 \mathrm{~A}$ \\
$T$ & Torque at MTPA $\alpha^{e}=60^{\circ}$ & $123 \mathrm{Nm}$ & $174 \mathrm{Nm}$ \\
\hline \hline
\end{tabular}

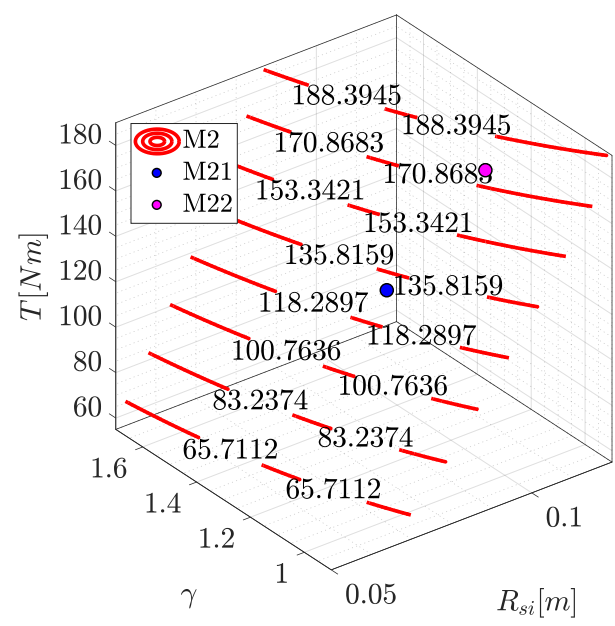

Fig. 16. General sizing at given rated current $\left(\mathrm{MTPA} \alpha^{\mathrm{e}}=60^{\circ}\right)$.
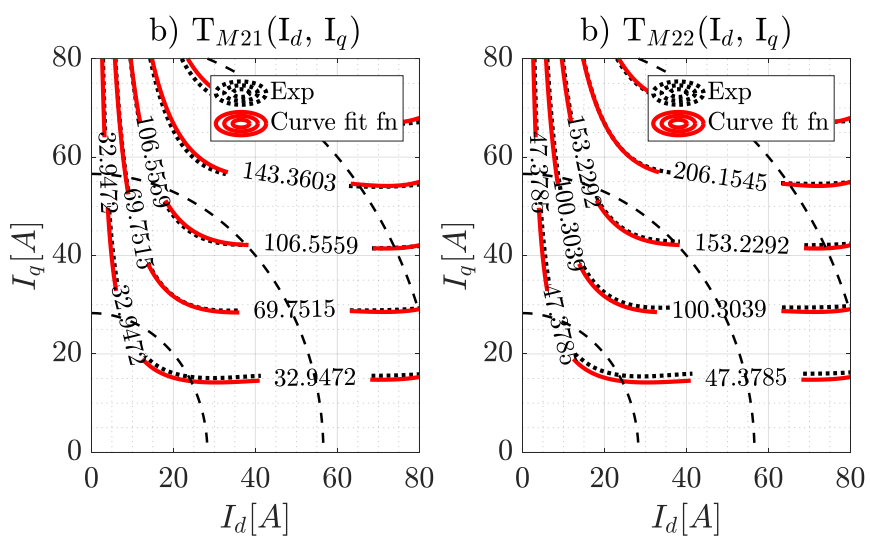

Fig. 17. Comparison of $i s o$-torque values.

As can be observed the experimental results for M21 and M22 at rated current $I_{s}=56.2 A$ and current angle $\alpha^{e}=60^{\circ}$ are lying on the same plane showing a very good match. The experimental operating points $\left(\mathrm{T}_{\mathrm{M} 21} \sim 127.1 \mathrm{Nm}, \mathrm{T}_{\mathrm{M} 22} \sim\right.$ 176.2Nm) are highlighted with dots for both machines in Fig. 17. Compared to the experimental torque values reported in Table VII, the torque errors are $3.2 \%$ and $1.3 \%$, for M21 and M22, respectively.

The function (34) is also useful to estimate the torque behavior on $i_{d}-i_{q}$ plane as well as to identify the MTPA at different saturation levels. In Fig. 17 this is derived for both M21 and M22 where the comparison of experimental and 
statistically calculated data is presented. This is showing the validity of equation (34) which results are in very good match with the experimental measurements.

\section{CONCLUSIONS}

This paper is proposing a novel generalized homothetic approach for a quick and accurate sizing of SynRel machines. Through this concept, the preliminary sizing process which usually comprises heavy FE iterations can be drastically reduced through the use of the proposed sizing equations. These equations were derived using regression techniques based on a wide range of analytically calculated data, for both radial and axial scaling. The MTPA of the SynRel machines have been analyzed and generalized for any size of the machine with the aid of the proposed analytical tool. Therefore, a consistent behavioral pattern between scaled geometries was defined, in order to derive the general sizing functions. These were validated by means of FE analysis as well as experimentally on 2 SynRel motors (M21 and M22), which are two scaled machines from the same reference geometry M2.

The experimental results obtained show a good match with respect to the curve fitting functions. At rated current and rated MTPA angle the error is about $\sim 4 \%$.

It can be concluded that the proposed method is defining a fast and accurate tool for the preliminary sizing and scaling of SynRel machines. This can be adopted by the industrial community, in particular when the performance assessment of a range of machine is required, starting from a reference design.

\section{REFERENCES:}

[1] N. Bianchi, M. Degano, and E. Fornasiero, "Sensitivity analysis of torque ripple reduction of synchronous reluctance and interior PM motors," IEEE Trans. Ind. Appl., vol. 51, no. 1, pp. 187-195, 2015.

[2] A. T. De Almeida, F. J. T. E. Ferreira, and G. Baoming, "Beyond induction motors-Technology trends to move up efficiency," IEEE Trans. Ind. Appl., vol. 50, no. 3, pp. 2103-2114, 2013.

[3] C. M. Donaghy Spargo, "Synchronous Reluctance Motor Technology: Industrial Opportunities, Challenges and Future Direction," Eng. Technol. Ref., vol. 44, no. May, pp. 1-15, 2016.

[4] N. Bianchi, S. Bolognani, D. Bon, and M. Dai Pre, "Rotor flux-barrier design for torque ripple reduction in synchronous reluctance and PMassisted synchronous reluctance motors," IEEE Trans. Ind. Appl., vol. 45, no. 3, pp. 921-928, 2009.

[5] G. R. Slemon, "On the Design of High-Performance SurfaceMounted PM Motors," IEEE Trans. Ind. Appl., vol. 30, no. 1, pp. 134-140, 1993.

[6] W. Soong, "Sizing of electrical machines," Power Eng. Brief. Notes, vol. 9, no. 2, pp. 17-18, 2008.

[7] S. Huang, J. Luo, F. Leonardi, and T. A. Lipo, "A general approach to sizing and power density equations for comparison of electrical machines," IEEE Trans. Ind. Appl., vol. 34, no. 1, pp. 92-97, 1998.

[8] M. Galea, C. Gerada, T. Raminosoa, and P. Wheeler, "A Thermal Improvement Technique for the Phase Windings of Electrical Machines," vol. 48, no. 1, pp. 79-87, 2012.

[9] C. Sciascera, P. Giangrande, L. Papini, C. Gerada, and M. Galea, "Analytical Thermal Model for Fast Stator Winding Temperature Prediction," vol. 0046, no. LCC, 2017.

[10] M. Murataliyev, M. Degano, and M. Galea, "A Novel Sizing Approach for Synchronous Reluctance Machines," IEEE Trans. Ind. Electron., vol. 0046, no. 2, 2020.

[11] I. Boldea, Z. X. Fu, and S. A. Nasar, "Performance evaluation of axially-laminated anisotropic (ALA) rotor reluctance synchronous motors," in Conference Record of the 1992 IEEE Industry Applications Society Annual Meeting, pp. 212-218.
[12] A. Tessarolo et al., "A heuristic homotetic approach to the dimensioning of induction motors from specification data," in 2014 AEIT Annual Conference-From Research to Industry: The Need for a More Effective Technology Transfer (AEIT), 2014, pp. 1-5.

[13] A. Tessarolo, M. De Martin, D. Diffen, M. Branz, and M. Bailoni, "Practical assessment of homothetic dimensioning criteria for induction motors," 7th IET Int. Conf. Power Electron. Mach. Drives, PEMD 2014, pp. 1-6, 2014.

[14] S. Nuzzo, M. Degano, M. Galea, C. Gerada, D. Gerada, and N. Brown, "Improved Damper Cage Design for Salient-Pole Synchronous Generators," IEEE Trans. Ind. Electron., vol. 64, no. 3, pp. 1958-1970, 2017.

[15] G. Pellegrino, T. M. Jahns, N. Bianchi, W. L. Soong, and F. Cupertino, The rediscovery of synchronous reluctance and ferrite permanent magnet motors: tutorial course notes. Springer, 2016.

[16] P. Ponomarev, Y. Alexandrova, I. Petrov, P. Lindh, E. Lomonova, and J. Pyrhonen, "Inductance calculation of tooth-coil permanentmagnet synchronous machines," IEEE Trans. Ind. Electron., vol. 61, no. 11, pp. 5966-5973, 2014.

[17] B. Gaussens, E. Hoang, O. De La Barrière, J. Saint-Michel, M. Lecrivain, and M. Gabsi, "Analytical approach for air-gap modeling of field-excited flux-switching machine: No-load operation," IEEE Trans. Magn., vol. 48, no. 9, pp. 2505-2517, 2012.

[18] G. De Recherche and U. H. Poincaré, "Comparison Between FiniteElement Analysis and Winding Function Theory for Inductances and Torque Calculation of a Synchronous Reluctance Machine," vol. 43, no. 8, pp. 3406-3410, 2007.

[19] J. Pyrhonen, T. Jokinen, V. Hrabovcova, and H. Niemela, Design of Rotating Electrical Machines. 2008.

[20] I. Boldea and S. A. Nasar, The induction machine handbook. CRC press, 2010.

[21] G. S. Hall, "Homothetic transformations with fixed points in spacetime," Gen. Relativ. Gravit., vol. 20, no. 7, pp. 671-681, 1988.

[22] A. Tuller, A modern introduction to geometries. Van Nostrand, 1967.

[23] R. R. Moghaddam and F. Gyllensten, "Novel High Performance SynRM Design Method an Easy Approach for a Complicated Rotor Topology.pdf," no. c, pp. 1-8, 2013.

[24] M. Degano, M. Di Nardo, M. Galea, C. Gerada, and D. Gerada, "Global design optimization strategy of a synchronous reluctance machine for light electric vehicles," 2016.

[25] C. Babetto, G. Bacco, and N. Bianchi, "Synchronous Reluctance Machine Optimization for High Speed Applications," IEEE Trans. Energy Convers., vol. 8969, no. c, pp. 1-8, 2018.

[26] M. Di Nardo, M Galea and C. Gerada, "Multi-physics Optimization Strategies for High Speed Synchronous Reluctance Machines," no. Im, pp. 2813-2820, 2015.

[27] M. Di Nardo, G. Lo Calzo, M. Galea, and C. Gerada, "Design optimization of a high-speed synchronous reluctance machine," IEEE Trans. Ind. Appl., vol. 54, no. 1, pp. 233-243, 2017.

[28] D. A. Freedman, Statistical models: theory and practice. cambridge university press, 2009.

[29] R. J. Freund, W. J. Wilson, and P. Sa, Regression analysis. Elsevier, 2006.

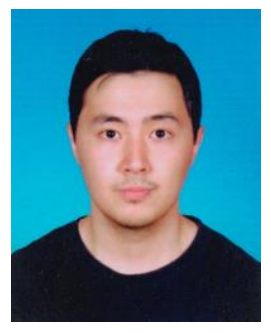

Mukhammed Murataliyev received his M.Sc. degree in electrical engineering from the University of Nottingham, Semenyih, Malaysia in 2016. He is currently pursuing a Ph.D. degree at the University of Nottingham Ningbo China and UK, with a focus on novel synchronous reluctance motor design and optimization methods. His main research interest includes modeling of synchronous reluctance and permanent magnet machines for industrial and aerospace applications.

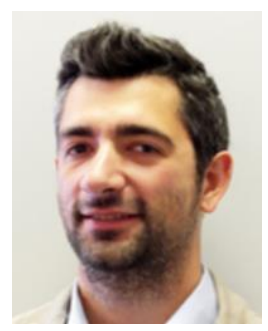

Michele Degano (M'15) received his Master'sdegree in Electrical Engineering from the University of Trieste, Italy, in 2011, and his Ph.D. degree in Industrial Engineering from the University of Padova, Italy, in 2015. Between 2014 and 2016, he was a postdoctoral researcher at The University of Nottingham, UK, where he joined the Power Electronics, Machines and Control (PEMC) Research Group. In 2016 he was appointed Assistant Professor in Advanced Electrical 
Machines, at The University of Nottingham, UK. He was promoted Associate Professor in 2020. His main research focuses on electrical machines and drives for industrial, automotive, railway and aerospace applications, ranging from small to large power. He is currently the PEMC Director of Industrial Liaison leading research projects for the development of future hybrid electric aerospace platforms and electric transports.

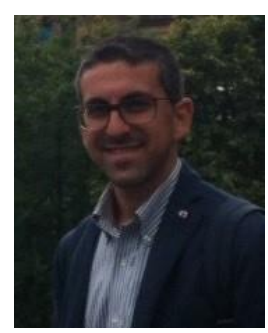

Mauro Di Nardo received the M.Sc.(Hons.) degree in electrical engineering from the Polytechnic University of Bari (Italy) in 2012, and the Ph.D. degree in electrical machine design from the University of Nottingham (UK) in 2017. From 2017 to 2019 he was head of the AROL research team within the Polytechnic University of Bari leading industrial R\&D projects on electrical drives design for mechatronics applications.

Since the 2019, he joined the Power Electronics and Machine Control Group of the University of Nottingham as Research Fellow. His research interests are the analysis, modelling, and optimizations of electrical machines, including permanent magnet and synchronous reluctance topologies for automotive and aerospace sectors as well as induction motor for industrial applications.

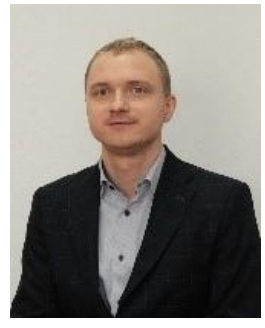

Dmytro Prystupa received the M.Sc. degree in electromechanical engineering from the National Technical University of Ukraine "Kyiv Polytechnic Institute," Kyiv, Ukraine, in 2011 and the Ph.D. degree in electrical engineering from the same university, in 2016.

In 2014, he became an Assistant Professor in the Department of electromechanical Systems Automation and Electrical Drives, National Technical University of Ukraine "Kyiv Polytechnic Institute." Since 2018, he has been a Senior Drive System Engineer in Nottingham Electrification Centre (NEC). His main research interests include control of electric drives, power electronics and electric vehicles.

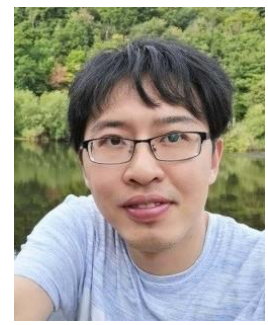

Shuo Wang (S'17-M'19) received the bachelor degree in automation from Hebei university of Technology in 2011, Tianjin, China, master degree in control science and engineering from Tianjin University in 2014, Tianjin, China, and Ph.D. degree in control science and engineering from Tongji University in 2019, Shanghai, China.

From 2017 to 2018, he became a Visiting researcher with Power Electronics, Machines and Control Group (PEMC Group), University of Nottingham, Nottingham, U.K. He is current working as a senior research fellow in university of Nottingham, Ningbo, China. His current research interests include high performance torque control, sensorless control and flux-weakening control used for permanent magnet synchronous machines, synchronous reluctance machines and permanent magnet-assisted synchronous reluctance machines.

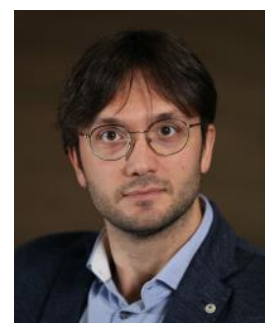

Giampaolo Buticchi received the Master degree in Electronic Engineering in 2009 and the Ph.D degree in Information Technologies in 2013 from the University of Parma, Italy.

In 2012 he was visiting researcher at The University of Nottingham, UK. Between 2014 and 2017, he was a post-doctoral researcher, and Guest Professor at the University of Kiel, Germany. During his stay in Germany, he was awarded with the Von Humboldt Post-Doctoral Fellowship to carry out research related to fault tolerant topologies of smart transformers.

He was appointed in 2017 Associate Professor in Electrical Engineering at The University of Nottingham Ningbo China and the Head of Power Electronics of the Nottingham Electrification Center. He was promoted Professor in 2020.

His research focuses on power electronics for renewable energy systems, smart transformer fed micro-grids and dc grids for the More Electric Aircraft. Dr. Buticchi is one of the advocates for DC distribution systems and multi-port power electronics onboard the more electric aircraft.
$\mathrm{He}$ is author/co-author of more than 200 scientific papers and an Associate Editor of the IEEE Transactions on Industrial Electronics, the IEEE Transactions on Transportation Electrification and the IEEE Open Journal of the Industrial Electronics Society. He is currently the Chair of the IEEE Industrial Electronics Society Technical Committee on Renewable Energy Systems.

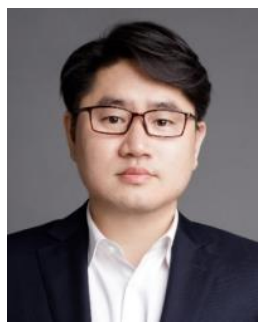

He Zhang (M'14-SM'18) received his B.Eng. degree in Control Science and Engineering from Zhejiang University, China, in 2002. He obtained the MSc. and Ph.D. degree in electrical machines from The University of Nottingham, UK, in 2004 and 2009 respectively. After this he worked as Research Fellow at the University and Director of BestMotion Technology Centre. He moved to University of Nottingham Ningbo China as Senior Research Fellow in 2014, promoted to Principal Research Fellow in 2016 and to Professor in 2020. Currently he is the Director of Nottingham Electrification Centre (NEC) within the Power electronics, Machines and Control research group in University of Nottingham. His research interests include high performance electric machines and drives for transport electrification.

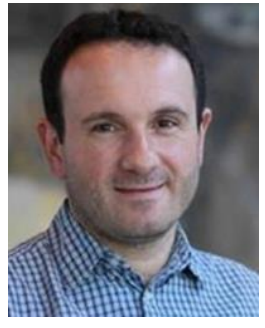

Chris Gerada (SM'12) is an Associate Pro-ViceChancellor for Industrial Strategy and Impact and Professor of Electrical Machines. His principal research interest lies in electromagnetic energy conversion in electrical machines and drives, focusing mainly on transport electrification. He has secured over $£ 20 \mathrm{M}$ of funding through major industrial, European and UK grants and authored more than 350 referred publications. He received the Ph.D. degree in numerical modelling of electrical machines from The University of Nottingham, Nottingham, U.K., in 2005. He subsequently worked as a Researcher with The University of Nottingham on high-performance electrical drives and on the design and modelling of electromagnetic actuators for aerospace applications. In 2008, he was appointed as a Lecturer in electrical machines; in 2011, as an Associate Professor; and in 2013, as a Professor at The University of Nottingham. He was awarded a Research Chair from the Royal Academy of Engineering in 2013. Prof. Gerada served as an Associate Editor for the IEEE Transactions on Industry Applications and is the past Chair of the IEEE IES Electrical Machines Committee.

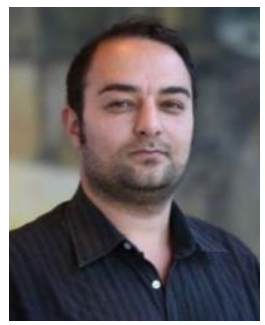

Michael Galea (M'13-SM'18, FRAeS) received his $\mathrm{PhD}$ in electrical machines design from the University of Nottingham, UK, where he has also worked as a Research Fellow. He is currently the Head of School of Aerospace in the University of Nottingham, Ningbo, China, where he is also the Director of Aerospace. He currently lectures in Electrical Drives and in Aerospace Systems Integration and manages a number of diverse projects and programmes related to the more / all electric aircraft, electrified propulsion and associated fields. His main research interests are design, analysis and thermal management of electrical machines and drives (classical and unconventional), the more electric aircraft and electrified and hybrid propulsion. $\mathrm{He}$ is a Fellow of the Royal Aeronautical Society and a Senior Member of the IEEE. 